\title{
Avrupa Tekstil Baskıcılığının Gelişiminde Türk Kırmızısı'nın Rolü
}

\author{
Leyla YILDIRIM *
}

\section{Özet}

1856 yılında ilk sentetik boyarmadde elde edilmiş olmasına rağmen tekstil sektöründe doğal boyaların kullanımı tamamen bitmemiştir. Boya sanayisi gelişirken yılların deneyimine dayalı boyama reçetelerine duyulan güven, doğal boyaların kullanımının bir süre daha devam etmesine neden olmuştur. Bu güvenin ardında boyaları elde etmek için harcanan zaman, para ve yoğun emek bulunmaktadır. Türk Kırmızısı reçetesi ise bunlar arasında özel bir yer tutmuş ve elde edilmesi için her çareye başvurulmuştur. Bu kırmızı rengin peşinde harcanan çabalar, Avrupa'da tekstil boya ve baskıcılığında büyük bir bilgi birikimiyle, kimya biliminin ve tekstil sektörünün gelişimini sağlamış ve Sanayi Devrimi'nin itici gücünü oluşturmuştur. Bu çalışmada Türk Kırmızısının elde edilme sürecindeki çabalara ve bir rengin sosyo-ekonomik değişime olan katkılarına değinilecektir.

Anahtar Sözcükler: Tekstil Tasarımı, Tekstil Baskııılı̈̊ı, Türk Kırmızısı, Kök Boya, Levant.

\section{The Role of Turkey Red in the Development of European Textile Printing}

\section{Abstract}

Although synthestic dyes were first produced in 1856, the use of natural dyes did not completely end up in textile business. As the dye industry progressed, the trust in recipes of dyeing which were based on years of experience, caused natural dyes to be used for a time. What lies behind this trust is the time, money and effort spent to produce dyes. The recipe of Turkey red occupied an important place among these and any serious effort was exerted to produce it. Such exertions enabled chemistry and textile sectors to progress with the help of significant knowledge in European textile dyeing and printing, and became the impulsive power of Industrial Revolution. This paper deals with efforts and attempts in the production of Turkey red and its contribution to socio-economic transition as a colour. 


\section{Giriş}

Antik dönemlerden beri gizemli görünüşü ve doğal zenginliği ile Doğu, sürekli bir ilgi odağı olmuştur. İpek, baharat, porselen vb. gibi Batı'da olmayan ürünler adına büyük keşifler ve seyahatler yapılmış, bu gizemli dünyaya ulaşmanın bedelleri ağır ödenmiştir. İlk atılan en önemli adımlardan biri Kubilay Han'ın güvencesinde Uzak Doğu ve bütün Çin'i dolaşan Marco Polo'nun (1254-1324) seyahatidir.

Gerçek olup olmadığı tartışılmakla birlikte, Rustichello tarafından kitap haline getirilen Polo'nun hikayeleri Batı'da Doğu'ya karşı büyük bir ilgi uyanmasını sağlamıştır (silk-road.com, 2014). Ardından Bartolomeu Dias'ın Afrika kıyılarına ulaşması ve Vasco da Gama'nın Hindistan seferi, Avrupalıların Asya ile direkt ticaret yolunu açmıştır. Bu ticaret yolunda çok çeşitli mallar olmasına rağmen öncelikli olanlar tekstiller ve üretiminlerinde kullanılan boyarmaddelerdir (Sardar, 2014).

Deniz yollarının açılması, sömürgeciliḡin yayılmasına neden olduğu gibi renk adına girişilen serüvenlerin de dönüm noktasını oluşturmuştur. Renkli tekstillere olan bu ilgi çeşitli rekabetlerle beraber bu uğurda birçok misyoner, kaşif ve bilim adamının büyük çabalar harcamasına yol açmıştır.

ilk olarak boyamacılığın nerede başladığı kesin olarak bilinmemekle birlikte boyamacılıkla ilgi en eski kayıtlar $M$. Ö. 4000 yıllarına kadar götürülebilmektedir. "Hindistan'da yapılan bir kazı sonucunda M. Ö. 3250-2770 yıllarına ait, kök boya türlerinden biri ile boyanmış olduğu düşünülen iki adet eflatun renkli pamuk elyafından yapılmış para keseleri bulunmuştur." (Karadağ, 2007: 8 ). "Büyük İskender M. Ö. 327'de Hindistan'daki güzel baskılı pamuklulardan sözetmektedir." (Druding, 2012). "Goffer'ın (1980) da ifade ettiği gibi, kök boya ile boyama sanatının doğu kökenli olduğu, Mısırlılara ve Perslere oradan da Yunanlılara ve Romalılara geçtiḡi düşünülmektedir." (Abdel-Kareem, 2012: 79-92'den). “Tutankhamon'un mezarında bulunan diğer tekstillerde olduğu gibi kemerinin de kök boya ile renklendirildiği tahmin edilmektedir. Yunanlı tarihçi Heredot kök boyanın Libya'da giysi yapımında kullanıldığından bahsetmiştir... Yunanca yazılan ilk boya ticaret kayıtlarında, Hindistan ve Anadolu arasında bu kökün ticaretinin yapıldığına dair bir kayıt bulunmaktadır." (Koren, 1993:5-31; Abdel-Kareem, 2012: 7992'den). “7. yüzyıl boyunca Paris yakınlarındaki St. Denis'de kök boya ekimi yapılmış, 15. yüzyılda ise Hollanda ileri gelen kök boya üreticisi olmuş, 16. ve 17. yüzyıllarda da üretime devam etmiştir. 1624 yılında yetiştirilmesiyle ilgili alınan bir patentten önce kök boyanın muhtemelen İngiltere'de yetiştirilmediği düşünülmektedir." (Prance and Nesbitt, 2005: 305). Çok farklı işlem aşamaları ile gerçekleştirilen bu süreçte, kök boyanın life sabitlenmesinde şap, temel mordandır.

"Yunanlıların bir mordan olarak şap kullandıkları, 15. yüzyılda İstanbul ve İzmir'de olmak üzere, Türkiye'de iki şap madeninin var olduğu bilinmektedir. Türklerin kök boya yetiştiriciliğini Balkanlarda geliştirdiği ve daha sonra Adrianpole veya Levant kırmızısı olarak bilinen bir işlemle kendilerine kumaş boyamaya başladıkları da söylenmektedir." (Prance and Nesbitt, 2005: 306). "1801 yılı basımı Encyclopedia Britannica, Osmanlı İmparatorluğu'nda üretilen pamukluluların güzel kırmızı renkleriyle dikkat çektiklerine işaret etmiş ve bu tekniğin Avrupa'ya 18.yüzyıl ortalarında getirildiğine değinmiştir." (Meller and Elffers, 1991:130). Tarihe bakıldığında kök boyanın birçok uygarlık tarafından bilindiği, eski çağlardan beri üretimi ve ticaretinin yapıldığı görülse de 16.-17. yüzyıllardan sonra pamuklu mallara olan talebin artması ve Doğu'dan Batı́ya doğru olan tekstil ticaretinin hız kazanması, Türk Kırmızısı'nın popüler olmasını sağlamıştır. Daha önceki yüzyıllarda ipekli kumaşları boyamada kullanılan hayvansal kaynaklı doğal boyarmaddeler, daha yaygın kullanıma sahip pamuklu kumaşlar için oldukça kıt ve pahalı olmaya başlamıştır.

Kök boya ile Türk Kırmızısı üretme girişimleri ise ilk olarak 1670 yılında Hollanda'da ve ardından 1680 yılında İsviçre'de başlatılmıştır (Riello, 2010). "17.yüzyılın başlarına kadar renklendirici kaynakları olarak bakkam ağacı (brazilwood), böceklerden elde edilen reçine (lac) ve kermes'le boyanmış kumaş parçaları görünmektedir." (Kirby and Whit, 1996: 56-80). 18. yüzyılda Doğulu ustaları Manchester ve Lyon bölgesine çekmek isteyen pamuk ustalarının araştırmalarının odak noktasını Türk Kırmızısı oluşturmuştur (Musson ve Robinson (1969: 339); Pérez and Verna, 2006, 539-565'den). Fukasawa (1987), pamuk baskıcılığının özellik- 
le de mordanla yapılan kök boya boyamacılığının ve indigo ile yapılan rezerve tekniklerinin Sanayi Devrimi'nin merkezinde yer aldığını belirtmiştir (Pérez and Verna, 2006: 536565'den).

\section{Türk Kırmızısı}

Türk Kırmızısı, (Ing.Turkey Red, Fr.Rouge de Turc, Rouge d'Andrinople-Edirne Kırmızısı) çok zahmetli bir boyama sürecini içeren ve uğrunda çok emek ve paranın harcandığı, sırrını çözene ödüllerin verildiği tarihsel bir renktir. Latince Rubia tinctorium L., (ing.Madder, Fr. Garance, Alm. Krapp) denilen çok yıllık kök boya bitkisinin köklerinden elde edilen kırmızı boyar madde.

Bazı yayınlarda Hint kırmızısı (Ing.Indian red ya da Fr. Rouge des Indes) olarak da adlandırılmaktadır (Lowengard,2006). Ancak, net olmamakla birlikte, kök boyanın Anadolu kökenli olduğu da söylenmektedir (Karadağ, 2007: 72). “Doğal yayııış alanı Kafkasya, İran, Orta Asya’nın batısııı ve kuzeybatı Himalayaları kapsamaktadır. Hindistan'da yetişen türü ise Indian madder olarak bilinen Rubia cordifolia L.'dır." (Karadağ ve Dölen, 2007: 583-589).

Sentetik boyaların keşfine kadar sadece tekstiller için değil, ressamların ünlü tabloları için de doğal kaynaklı reçeteler hazırlanmış ve bunların arasında kırmızı renk maddesi (red lake) özel bir yer tutmuştur (Kirby ve Whit, 1996; Kirby vd. 2007). "Yaklaşık 1400 ve 1890 yılları arasındaki kırmızı boya hazırlanmasında kullanılan reçeteler gözden geçirildiğinde en sık adı geçen boyar maddelerin, bakkam ağacı, kök boya, kermes, koşnil ve lak olduğu görülmektedir. Ayrıca çeşitli kermes kaynakları ya da farklı koşnil türleri ile boyanmış olabileceği düşünülen kırmızı kumaş parçalarından da kırmızı boya elde edilmiştir." (Kirby, 1987: 12-18; Kirby ve Whit 1996: 56-80'den). Bu durum, o dönemde boyar maddelerin ne kadar değerli olduğunun bir göstergesidir. "Türk Kırmızısı üzerine yapılan çalışmaların bir başka sebebi de sadece İspanya'nın elinde bulunan, hayvansal kaynaklı doğal boyarmadde olan koşnile uygun bir alternatif aranması olmuştur." (Galan, 2001; Kirby vd., 2007: 69-95'den).

Avrupa pamuk baskıcılığı endüstrisinin gelişimi sadece üretim süreci bilgisine dayanmamış aynı zamanda yeni bo- yalar ve mordanlarla ilgili deneyimi de içermiştir. Özellikle kök boya ya da Türk Kırmızısı ve indigo bunlar arasında iki temel rengi oluşturmuştur. George Souza (2004: 40-58), renklendirme maddeleri ve boyalardaki uluslararası ticaretin, erken modern dünya ekonomisini karakterize eden küreselleşmenin ayrılmaz ilk aşaması olduğunu savunmaktadır. Kırmızı, erken dönem modern dünyada yaygın olarak işlem gören kermes, koşnil, kök boya, bakkam ağacı ve lak gibi çeşitli maddelerden üretilmiştir (Souza, 2004: 40-58; Riello 2010: 1-28'den). Kırmızı rengi elde etmek için birçok doğal kaynak kullanılmakla birlikte, renk tonu açısından aralarında farklılıklar bulunmakta, bunlar kırmızının maviye veya sarıya doğru kayan çeşitli değerlerini vermektedirler.

"Türk Kırmızısı, Avrupa kök boyamacılığındaki tuğla kırmızısından (dark scarlet ya da brick reds) farklı olarak koyu parlak kırmızıya (carmine) yakın bir renk vermekte ve yünden daha çok, pamuk boyamada kullanılanılan işlemleri içermektedir.” (Lowengard, 2006). "Türk Kırmızısı, kök boyadan üretilen parlak ve dayanıklı en ünlü renk tonunu ifade ettiği gibi" (Prance ve Nesbitt, 2005: 306), "bir renkten çok, kırmızı renkli tekstillerde kulllanıldığı şekliyle, parlak rengi elde etmek için uygulanan bir süreci de ifade etmektedir." (Nenadic ve Tuckett, 2013).

“Pamuk kullanımı Fransa’da yaygınlaştığı zaman, bu Hint kırmızısının ya da Türk Kırmızısının, daha çok Edirne kırmızısı adıyla tanınan kırmızının sırrını çözmek bir zorunluluk halini almıştır." (Delamare, Guineau, 2007: 91).

Türk Kırmızısı için, Hindistan kökenli olduğuna, bazen Hint kırmızısı olarak daha doğru şekilde adlandırılması gerektiğine vurgu yapılsa da, kırmızı rengi elde etmek için birçok bölge, kendi endemik bitki ve hayvan kaynağından yararlanmışır. Kendine özgü kaynakların kullanımının yanı sıra aynı boyar madde için farklı adlandırmalarla karşılaşılmaktadır. Bu adlandırılmalar, boyar maddenin ticaretinin yapıldığı bölgenin özelliğine, tüccarların kimliği ve diline, rengin kullanımına, rengin üne kavuşması ve pazardaki talep konumuna vb. birçok etmene bağlı olarak değişmektedir. Bunların dışında boyamayı yapanlarla, kayıtları tutanların farkı kişiler olmaları da bilgi aktarımında bazı aksaklıklara neden olmuştur. Örneḡin Hindistan'ı ziyaret eden gezginler, tekstil 
üretim sürecine bir tekstilci gözüyle bakmadıklarından ve diller arasında bazı sözcüklerin tam karşıı̆ı olmadı̄̆ından anlattıkları süreçlerle ilgili bazı bilgiler tam anlaşılmamışırı.

Tekstil tasarımı açısından bakıldığında ise madder ile Türk Kırmızısı́nın ayrı kategorilerde değerlendirildiği görülmektedir. Madder başığı altında; kök boyası ile farklı mordanlar kullanılarak elde edilen, kırmızdan pas rengine, turuncu tondan kahverengiye kadar geniş bir yelpazedeki, o dönemde basılan çiçekli ve geometrik desenler ele alınırken Türk Kırmızısı için canlı, parlak, koyu kırmızı tonunda üretilen etnik desenler ele alınmıştır. 'Buradaki ayrım boya ve baskı süreçleriyle ilgili olup, Türk Kırmızısı grubundakilerin özel işlem basamaklarıyla elde edilmesinden kaynaklanmaktadır. Desenler açısından bakıldığında ise Türk Kırmızı olarak adlandırılan grubun Doğu kökenli tasarımları içerdiği görülmektedir. Dolayısıyla Avrupa tekstil desen tarihinde Türk Kırmızısı, üretim şekliyle farklılıklar gösteren ayrı bir tasarım tipini ifade etmektedir.

Kök boya kullanımı, Türk Kırmızısı ile ünlü olmadan önce de Avrupa'da bilinmektedir. Ancak, Avrupalılar canlı parlak kırmızı yerine kök boya ile kahverengi tonlarında renkler elde etmekteydiler. Pamuklu malların kullanımın artması, kök boya ile yünün boyanmasından farklı bir boyama sürecinin uygulamasını zorunlu hale getirmiştir. Avrupa'da madder olarak bilinen kök boya, Anadolu'dan parlak kırmızı renk tonu elde etme deneyiminin aktarılmasından sonra farklı işlem basamakları ile uygulanmış ve zorlu çabaların sonucu Türk Kırmızısı denilen parlak canlı renk tonu elde edilebilmiştir. Dolayısıyla Avrupa tekstil tasarımlarını içeren kaynaklara bakıldığında Türk Kırmızııı başlığı altında, yine kök boya (madder) kullanılarak üretilmiş baskılı teksiller görülebilmektedir. Bu tipteki tekstiller renkleri ve desenleri ile farklılık göstermektedirler. Ayrıca, Türk Kırmızısı denildiğinde sadece bir renk tonu değil özel boyama adımları içeren bir teknik de anlaşılmakta ve Avrupa baskıcılık tarihinde ayrı bir yer tutmaktadır.

\section{Avrupa'nın ilk Bilgilere Ulaşmasında Gezginlerin ve Görevlilerin Rolü}

Kök boyanın kullanımı yüzyıllar öncesine dayansa da, zenginliğin soyluların elinde olması bu boyaya alternatif daha başka kırmızı boya kaynaklarının kullanımını öne çıkarmışır. Avrupa'nın Hint boyalı ve baskılı kumaşlarını ithal etmesi, orta sınıfın zenginleşmesi ve daha çok üretim için daha ucuz boya kaynaklarına ihtiyaç duyulması, kök boya talebini arttırarak aranan bir boya olmasını sağlamıştır. Birçok türü bulunmakla birlikte kök boya, Rubia tinctorium L. olarak bilinen türü ve Türklere atfedilen renk tonuyla 18. yüzyılda üne kavuşmuştur.

"17. yüzyılın üçüncü çeyreg̃ine kadar Avrupalıların Hint baskıcılığı ile ilgili bilgileri Portekizli gezgin Duarte Barbosa ve Fransız gezgin François Bernier'in derme çatma ve yetersiz bilgilerine dayanmaktaydı... Yüzyılın sonlarına doğru gittikçe artan sayıda boyalı ve baskılı pamukluların Avrupa'ya gelişi, bu malların üretim süreçlerine olan ilgiyi canlandırmıştı." (Riello 2010: 1-28). Ancak, boyalı ve baskılı mallara olan talebin canlanması ve ithalatın gittikçe artması ülkelerin ekonomisini özellikle de Fransa'nınkini oldukça etkilemiştir. Ulusal ekonominin gelişmesi için ithalat yerine ihracatın arttırılması ve buna bağlı olarak da yerel üretimin oluşturulması konularında birtakım girişimler başlatılmıştır.

"Tarihçiler 17. yüzyııın sonlarından itibaren vergi ve yasaklarla ilgili alınan merkantalist önlemlerin Avrupa tekstil baskıcııı̆ııın gelişmesini teşvik ettiğini savunmuşlardır." (Wadsworth ve Mann: 1932; Riello 2010: 1-28'den). Bir yandan ekonomiyi korumak için alınan önlemler öte yandan halkın bu mallara olan ilgisinin artması, yerel üretimin geliştirilmesini zorunlu hale getirmiştir. Üretim için bilgilerin yeterli olmayışı ise hem tüccarların hem de kraliyetin çeşitli yollara başvurmasına neden olmuştur. Devlet tarafından görevlendirilmiş kişiler boyama ve baskı süreçlerinin detaylı bilgilerini, kaleme aldıkları el yazmalarıyla aktarmaya çalışmışlardır. "1678 ve 1680 yılları arasında, Georges Roques, Ahmedabad, Burhanpur, ve Sironj'daki tekstil üretiminin detaylı bilgisini içeren 333 sayfalık bir el yazması kaleme almıştır. Fransız Doğu Hindistan Şirketi'nde görevli Antoine Georges Nicolas de Beaulieu (1692-1764) ise 1734 yıllarında derlenen ikinci bir el yazması hazırlamıştır." (Schwartz, 1956: 7; Riello 2010: 1-28'den).

Roques'un el yazması 1966 yılında Paris'teki Ulusal Kütüphane arşivlerinde bulunarak gün yüzüne çıkmıştır. Roques'un raporu tekstille ilişkili olmayan birçok konuyu içerse de daha çok pamuk boyama ve baskıcılığı için çaış̧ıldı̆ını göstermektedir. 1734'de yazılmış Beaulieu'nün el yazması ise 17.yüzyıl sonu ve 18.yüzyıldaki Hindistan 
baskıcılığını anlatanlar arasında belki de en başarılısıdır... Beaulieu'nün analizlerini bu kadar önemli kılan sadece tüm detayları kusursuzca anlatması değil; aynı zamanda bu el yazmasının Avrupa'da dolaşmasıdır. Buradaki bilgiler Chevalier de Querelle'in Traité sur les toiles peintes-1760) ve Jean Rhyner'ın Matériaux pour la coloration des étoffes-1766 (1865'de yayınlanan) adlı çalışmalarında kullanılmıştır (Riello 2010: 1-28)

"Roques ve Beaulieu'den sonra Hindistan'daki tekstillerle ilgili önemli bilgiler aktaran üçüncü belge, 1742 ve 1747 yılları arasında Hindistan'da yaşamış misyoner Père Coeurdoux'nun mektuplarından oluşmaktadır." (Robinson, 1969: 112; Riello 2010: 1-28'den). Bu belgeler ilk kaynakları oluşturmuş, ancak üretim için yeterli bilgi sağlayamamışlardır. O dönem için boyama ve baskıcılık sadece teorik bilgi ile gerçekleştiremeyecek kadar karmaşık ve zahmetli işlemlerden oluşmaktadır. Başarılı bir sonuç için, Uzak Doğu'dan sağlanan bilgilerle Yakın Doğu'nun deneyiminin sentezlenmesi gerekmiştir.

\section{Anadolu'nun Önemi ve Türk Kırmızısı Uğruna Verilen Mücadeleler}

"16. yüzyılda Avrupa tekstil üreticileri sulu ve yağlı boyalarla keteni boyayarak Hindistan tekstillerini taklit etmeye çalışmışlardır. (Floud, 1960: 275; Riello 2010: 1-28'den). "1619 yılında George Wood, ketenin boya ve baskısıyla ilgili 21 yıllık bir patent alarak Avrupa'da tekstil baskı endüstrisinin gelişimi ile ilgili girişimlerden birini başlatmıştır." (Turnbull, 1947: 18; Riello 2010: 1-28'den). "Ancak, bu ilk örnekler oldukça kaba ve renkleri kalıcı olmaktan uzaktırlar." (Raveux, 2004: 157; Riello 2010, 1-28'den). Bu tip başarısız girişimlerin ardından daha verimli bir uygulamaya geçene kadar birçok örnekle karşılaşmak gerekmiştir. $O$ dönem için Fransa'nın güneyi Avrupa'ya açılan önemli bir noktadır.

"On altıncı yüzyıldan itibaren Marsilya, Hindistan'dan, İran'dan özellikle de Osmanlı İmparatorluğu'ndan pamuklu kumaşların ithal edilmesinde Avrupa'nın başlıca şehirlerinden biri olmuştur. On yedinci yüzyılın ilk yarısında özellikle Diyarbakır'ın basmaları (chafarcani ${ }^{2}$ ), İzmir'in ince pamukluları (boucassin ${ }^{3}$ ), Halep'in mavi kumaşları bölgede aktif bir ticaretin önemli konusu olmuşlardır." (Raveux, 2008: 37-51). "Marsilya, Londra ve Amsterdam'dan önce üretime başlamasıyla Avrupa'nın en eski baskılı ve boyalı tekstillerini üreten merkezi olarak kabul edilmektedir" (Chapman et Chassagne, 1981: 6-9; Raveux, 2008: 37-51'den). “Burada tekstil boyama ve baskıcılığının ortaya çıkması, aslında pamuk kıtlığının yaşandığı bir döneme denk gelmiştir. 17. yüzyılın ortalarında Marsilya'da ticaret yapmak oldukça zordur. Veba, bölgesel savaşlar ve Osmanlı İmparatorluğu ile ticaretin tamamen kopması nedenleriyle gerçek bir çöküntü yaşanmıştır." (Masson, 1896: 131 ; Raveux, 2008: 37-51'den). Baskılı mallara olan talep ise yerli endüstrinin kurulmasını zorunlu hale getirmiştir.

"1659 yılına kadar ham bez, kök boya, indigo, alum, mazı ve arap zamkının gelişi oldukça düzensiz olduğundan Marsilya'daki boyalı ve baskılı tekstillerin üretimi ilk on yılda oldukça yetersiz kalmıştır. Bu durum 1660 yılından itibaren iyileşmeye başlamış ancak Levant ile ticaretin yapısı düzgün olmadığından zorluklar devam etmiştir... Avrupalılar Doğu'nun kumaşlara yaptığı bitim işlemini, mordanların hazırlanmasını ve uygulanmasını özellikle de kök boya ile kırmızı elde etmenin sırlarını öğrenmekte zorluk çekmişlerdir. Marsilya'da uygulanan teknikler güneşe ve yıkamaya dayanıksız boyalı ve baskılı kumaşlarla kötü sonuç vermiştir." (Raveux, 2008: 37-51).

Temel mordan olan şap ise 17. yüzyılda Avrupa'da hala kıttır. Elde edilen tekstil mamülü ise Hint tekstillerinden oldukça uzak, desensiz ve tonsuz tek renkli bir kumaştır (Turnbull, 1947: 18; Riello, 2010: 1-28'den).

"Pamuklu tekstiller üzerine uzman olan akademisyen Paul Schwartz 1960 yılında, Avrupa'nın renkli tekstil üretimi yapma konusundaki yeteneḡinin Yakın Doğu'dan özellikle de Türkiye'deki atölyelerde yapılan uygulamalardan geçmiş olduğunu öne sürmüştür.” (Riello, 2010: 1-28). Bu yerlerin en önemlilerinden olan Diyarbakır, kırmızı ve mor renkli zeminli, büyük olasılıkla Sironj ve Ahmedabad'da üretilen jafracani'lerin taklitleri olduğu düşünülen ve chafarcani adı verilen çiçek baskılı kumaşlarıyla ünlüdür." (Fukasawa, 1987: 46; Raveux, 2008: 23-5; Riello, 2010: 1-28; Faroqhi, 2005: 1719'den). Fukasawa, Raveux, Riello ve Faroqhi gibi yazarların 
belirttiği gibi Hindistan'da üretilen jafracani' adı verilen basmanın benzeri Diyarbakır'da üretilmiş ve diller arasındaki farklılılardan dolayı baskılı bu kumaşa chafarcani denilmiştir.

"Chafarcani üretimi için gerekli olan tekniğin İran yolu ile Kuzey Hindistan'dan, muhtemelen aktif ticaretle uğraşan Ermeni tüccarlar tarafından taşınarak geldiği varsayılmaktadır. Fransız arşiv kaynaklarında iyi bir şekilde belgelendiği gibi kırmızı bogasi ile birlikte bu tip pamuklular Anadolu tüccarlarının ticaretinde önemli bir sermaye oluşturmuşlardır." (Yılmazçelik, 1985: 311; Faroqhi, 2005: 17-19'den). “Ermeni tüccarlar Diyarbakır'ın yanı sıra Malatya ve Çelebi gibi diḡer yakın merkezlerden Fransa ve Doğu Avrupa'ya özellikle de Polonyáya baskılı pamuklular satmışlardır (Fukasawa, 1987: 48; Riello, 2010: 1-28'den).

“Türkiye, Ermenistan ve Gürcistan’a yaptığı iki yıllık bir gezinin ardından Fransa'ya dönen doktor ve botanikçi J.Pitton de Tournefort çalışmasında, (Relation d'un voyage au Levant fait par ordre du roi par M. Pitton de Tournefort-Amsterdam 1718) her yıl Tiflis'ten ve Gürcistan'ın geri kalan yerlerinden iki yüz deve yükünden fazla, boia adlı kökün Erzurumaa, oradan da Polonyáya boyalı kumaş satan Diyarbakır’a gönderildiğinden söz etmektedir. Gürcistan aynı kökü Hindistan için de üretmektedir... J. Clouet ve Jos. Depierre'in sözlüg̈ünde (Dictionnaire Bibliographique de la Garance -Paris 1879) boia (boya) madder' in Türkçe ismidir." (Shwartz, 1969: 14-15).

Bir yabancı tüccar ya da bir gezgin için o dönemde boya sözcüğü, kök boya yani madder ile aynı anlama gelmekte ve bu malzeme, uluslararası bir ticaret malı olarak işlem görmektedir. Buradan da kök boyanın ticari bir mal olarak işlev gördüğü düşünülebilir. Bir yandan boyalı malların ticareti devam ederken bir yandan da Türk Kırmızısı boyama yöntemi araştırılmaya devam etmiş ancak hemen başarılı bir sonuç elde edilememiştir. Tüm bireysel çabalara rağmen gelişmeler oldukça yavaş olmuştur.

"1740 yılında Fransa, her yıl Levant'dan 5000-6000 balya kırmızı kumaş ithal etmekteydi. Hatta kendi yerli üretiminin bir parçası olan yünlü ve pamukluları, boyanmak üze- re, kök boya/Türk Kırmızısı'nı başarıyla üreten Türkiye'ye göndermekteydi. Fransız topraklarında Türk Kırmızısı üreten boyahanelerin Levant'dan gelen Yunan ve Türk boyacılarla kurulması girişimi şaşırtıcı değildir. Kök boya, indigo ve Hindistan'dan çok daha fazla Türkiye'nin özellikle de kullanımı ve ticari sömürüsü hakkında kesin bilgi sağlayan Levant'in uzmanlık alanı olmuştur." (Lowengard, 2006; Riello, 2010: 1-28'den).

"Avrupalılar Türk Kırmızısı'ı elde etmek için 1740 yılına kadar çok çaba harcamışlar ve birçok problemle karşılaşmışlardır. Türkiyéde uygulanan boyama süreci yoğun emek gerektirmekteydi ve pahalıydı. Birçok ön işlemin ardından boyama bazen haftalarca sürmekteydi. Ayrıca bu boyama sürecini 18.yüzyıl Avrupa'sındaki baskı ve boyama tekniklerine uygulamak çok da kolay değildi. Avrupa'daki Türk Kırmızısı üretimi 19.yüzyıl pamuk endüstrisinin bir başarısı olarak kabul edilmektedir. Bu rengin üretiminde endüstrinin gelişmesi için gerekli olan tekniklerin ve üretim süreçlerinin transfer edilmesi eş zamanlı bir çabanın sonucundadır." (Lowengard, 2006).

Bu renk, başarılı olarak ilk defa Fransa'da 1740 'ı yıllarda üretilmiş, Adrianople-Edirne Kırmızısı olarak yeniden adlandırılmış ve izleyen yıllarda da boyama, mordanlama ve beyazlatma teknikleriyle ticari olarak uygulanabilir hale getirilmiştir. Liliane Pérez, Yakın Doğu'daki kök boya üretimin kopyalanmasında ve madderin özelliklerinin Avrupa'da ögrenilmesinde etkili olan gezgin, girişimci ve mucit Claude Flachat'ın hayatını araştırmıştır. Flachat, Levant'da uzunca bir süre kaldıktan sonra 1756 yılında Fransa’ya dönmüş ve Lyon'dan çok uzakta olmayan Saint-Chamond'da bir Türk Kırmızısı boyahanesi kurmuştur. Türk bir boyacı ustasını, Edirne'li iki boyacıyı, İstanbul'dan iki kalaycıyı, İran'lı bir eğirmeciyi, İzmirli bir hallacı ve iki Ermeni mordan ustasını işe almıştır (Pérez, 2002: 105; Riello 2010: 1-28'den). Bir başka kaynağa göre ise 1747 yılında M.Fesquet, Goudard ve d'Haristoy, yanlarına aldıkları boyacılar ile biri Rouen yakınlarındaki Damétal'da, diğeri ise Languedoc'daki Aubenas'da olmak üzere iki işletme kurmuşlar; Flachat, bunlardan dokuz ay sonra üçüncü bir işletmeyi kurmuştur. ${ }^{4}$ Türk Kırmızısı́nın Edirne Kırmızısı olarak yeniden adlandırılmasında belki de 
bu Edirneli boya ustalarının payı olmuştur.

Bireysel girişimlerin yanında devlet desteğiyle de bir takım çalışmalar yapılmaktadır. "1750 yılında Lyon'lu boyacı François Gonin, yerel üretim müfettişleri, ticaret odası, loncalar ve girişimciler tarafından denetlenen, pamuk boyamacılığında geliştirmiş olduğu yeni yönteminin denemelerini yapmak için Rouen'e gönderilmiştir. Burada çırak yetiştirmiş ve bir akdemisyen olan Hellot tarafından becerileri incelendikten sonra da usta olmuştur." (Pérez, 2000; Pérez and Verna, 2006: 539-565'den). "Türk Kırmızısı zamanla Avrupa'nın diğer yerlerine kısmen Levant'dan gelen işçilerle yayılmıştır. 1768 yılında iki Amsterdam'lı tüccar, Hollanda'da yaşayan bir Türk usta ile beraber Türk Kırmızısı boyahanesini açmışlardır” (Driessen,1944:1749, Riello 2010:1-28'den). "Bununla beraber teknik, aḡırlıklı olarak Fransa'dan öğrenilmiştir. Zurich'den Johann Zeller, Nîmes'de çalıştıktan sonra 1760’lı yılların başlarında İsviçre'de Türk Kırmızısı boyahanesini açmıştır" (Aikin, 1795: 165; Riello, 2010: 1-28'den). Boyama ile ilgili birçok sonucun ve reçetenin dolaşması, birtakım düzenlemeler yapılmasına neden olmuştur. Fransa'da 1765 yılında Imprimerie Royale bu boyama ile ilgili bir talimatname basmıştır (Lowengard, 2006).

"Talimatnameyi basmadaki amaçlardan biri de kök boya üretiminde belli bir kaliteyi yakalama isteğidir. Çünkü birçok boyacı, orjinal Andrianopolis kırmızısını ya da, o dönemde boyacılar tarafından Adrianopolis olarak adlandırılan rengi elde edebildiklerine inanmıştır. Ancak çok azı, bu özel işlem gerektiren Türk formulünü başarabilmiştir. 1777 yılında Flamanca yazılmış ve Fransızca çevirisi Mémoire sur la teinture en noir olan bir kitapçıkta bu konuya değinilmiştir. Fransız kimyacı Hellot çeşitli yerlere gönderdiği notunda yapacağı bir testle taklit Türk Kırmızılarını hemen imha edebileceğini yazmıştır." (Brunello, 1973: 234).

“Fransa'da yararlı bir uygulama yalnızca 1776 yılında Pouce ve Archalat adında iki Parisli tüccarın devlet desteḡi ile Adrianople'dan (Edirne) birkaç Yunanlı boyacıyı kiralamasıyla başlatılmıştır. Bu insanlar Darnetal'da varolan boyahane etrafında bir topluluk oluşturmuşlardır." (Howcraft, 2013).
"1783 ve 1791 yılları arasında ise Türk Kırmızısı üretim süreci ile ilgili onlarca izin alınmış" (Lowengard, 2006) ve böylesine peşinden koşulan bir renk için, çok fazla endüstriyel casusluk olayı yaşanmıştır. Belki de gerçek reçetenin saklanması için farklı farklı reçeteler piyasada dolaşmıştır. Teknik, Anadolu'dan Fransa'ya geçse de Avrupa'daki rekabet, her ülkenin kendine göre bir takım avantajlar sağlamasına neden olmuştur.

“Fransa'da bir baskı fabrikası bulunan sanayici Oberkampf, yöntemlerini geliştirme isteğiyle rakiplerinin boyama teknikleri ayrıntılarını ögrenmek için yeğenlerini Glascow’a yollamıştır. İngiltere ve Fransa arasındaki ekonomik savaştan dolayı mektupların ve belgelerin sınırdan geçirilmesi için her şey, sahte kırmızı boyayla renklendirilmiş bir şap eriyiğle pamuklu kumaş üstüne yazılmış ya da çizilmiştir. Sirkeye batırıldığında bütünüyle kaybolan yazı ve çizimler, şap emdirilmiş kumaşın gideceği yere vardıktan sonra kök boya ile boyanmasının ardından tekrar okunabilir hale gelmiştir." (Delamare ve Guineau, 2007: 141).

Dolayısıyla kök boya ile boyama yöntemi hem bir casususluğun ana sebebi olabileceḡi gibi, boya endüstrisindeki sırların öğrenilmesi için bir casusluk tekniği olarak da kullanılmıştır.

“Ingilizler 1770 civarından itibaren karşı kıyılardan bu teknolojiyi ithal edebilmek için büyük çaba harcamışlardır... Louis Borelle bu uygulamanın tanıtımını yapmak için 1781 yılında Fransa'dan İngiltere'ye gelmiştir... İngiltere hükümeti İngiliz endüstrisinin yararına sırlarını ortaya çıkarması için Fransız Borelle ve kardeşine 2500 E ödemiş ancak uygulama başarılı olamamıştır (Travis, 1994: 28).

"1780'lerin ortalarında ticaretteki geçici durgunluktan dolayı, çoğu Normandiya'dan birçok Fransız boyacı İngiltere'ye göç etmiştir. 1786 yılında Manchester'ı ziyaret eden Normandiya Ticaret Odası'nın durum tespit komisyonuna göre yaklaşık yirmi kadar boyacı buraya yerleşmiştir" (Howcraft, 2013). "Bu göçmenlerden en iyi tanınanı Pierre Jacques Papillon'dur. Papillon, 1785'de Manchester tekstil komitesinin önde gelen üyesi Mr. Philips'e bir mektup yazmış ardından ziyaretine gitmiştir ancak Türk Kırmızısı'nı bo- 
yayabilme yeteneği Mr. Philips'i memnun etmesine rağmen Manchester Ticaret Odası Türk Kırmızısı yöntemini halkın kullanımına yaymak için, 1781 yılına doğru İngiltere'ye gelen ve $2500 E^{\prime} l u k$ prim alan Borelle'le çoktan görüşmüştür. Papillon da, Glasgow'un önde gelen iş adamlarından David Dale ve George Macintosh'la bir ortaklık kurmuş, kısa sürede birçok kişi onlara katılmıştır." (Colouring the Nation, 2013).

"The Society of Arts Türk Kımızısı ile ilgili 1785 yılından önce on sekizden fazla başvuru almıştır. Manchester'da boyacı olan John Wilson, 1761 yılında, en iyi Türk Kırmızısı́ı ürettiği, iki yıl sonra da daha parlak renk elde ettiği için dernekten iki kez ödül kazanmıştır." (Lowengard, 2006).

"Wilson daha sonradan kaleme alınmış bir ifadesinde bu değerli rengi elde etmenin ona birkaç yüz pounds'a patladığından söz etmiştir. Bu rengin reçetesini elde edebilmek için 1753 yılında genç bir adamı Türkiye'ye göndermiştir. Bu kişi Yunanca ögrenmiş ve Smyrna’da (İzmir) bir tüccar olan Mr. Richard Dobs'la beraber kalmıştır. Ancak Wilson, ürettiği ne pamuklu kadife ne de diḡer ürünler için iyi sonuç alamadığından hayal kırıklığı yaşamıştır. Wilson'un başarısızlığının nedeni, önce iplik boyamadan daha zor olan parça boyamayla ilgilenmesi olmuştur." (Howcraft, 2013).

"Boyama sürecinde kullanılan yağın uygulama zorluğundan başlangıçta yalnızca pamuk iplikleri boyanabilmiş kumaş boyama ise işlemin geliştirilmesiyle 1810 yılından sonra başarılabilmiştir." (Eddy, 2012). "Türk Kırmızısı üretme konusunda imtiyaz sahiplerinden biri olan Emanuel Osmont, kendi tekniklerini üretim sürecine uygulayarak Smyrna pembesi adını verdiği bir tonu elde ederek bir ödül kazanmıştır. Bu keşif, Türk Kırmızısı konusunda uzmanlaşmış, bir boyahaneye sahip, Louis-Auguste Dambourney'in ilgisini çekmiştir. Genelde boyama sürecini değiştirerek farklı renkler elde etmek alışılagelmiş bir durum değildir." (Lowengard, 2006).

"Baskılı pamuklara olan ilgi, özellikle de Türk Kırmızısı'nın üretimi, 19. yüzyıl İskoç tekstil endüstrisinin gelişmesinde önemli bir rol oynamıştır. Renkli ve yıkanabilir olması ile pamuk, iş̧̧i sınıfının moda tüketimine katılmasını sağlamıştır. illk küresel emtia olan pamuk, Ortaçağ’dan iti- baren Hindistan'dan Avrupa'ya doğru yol almış ancak büyük ölçüde yaygınlaşması Doğu Hindistan Şirketi'nin yaptığı ticaretle 18. yüzyılda olmuştur." (National Museums Scotlnad, nms.ac.uk, 2013b). 19. yüzyıl boyunca The Vale of Leven'da (Dunbartonshire-iskoçya) binlerce işçi, dünyanın birçok yerinde satılmak üzere parlak, solmaz, göz alıcı Türk Kırmızısı ile boyanmış tekstilleri üretmişlerdir.

"19. yüzyıl, iyi bir tasarımın nasıl olacağı konusunda birçok tartışmaya tanıklık etmiştir. Özellikle Fransa ile karşılaş̧ıııldığında Ingiltere'de bu alanda sayısız girişim gerçekleştirilmiştir. İskoçyánın Türk Kırmızısı üreticileri de bu tartışmada yer almışlar, 1867 yılındaki Paris Sergisi dahil olmak üzere birçok büyük sergiye katılmışlar ve Journal of Design and Manufactures dergisinin 1849'dan 1852'ye kadar olan kısa varlığında ilk tasarımlarından bazılarını yayınlamışlardır. Ancak Türk Kırmızısı endüstrisi ucuz, hoş, boyalı ve baskıı pamuklu kumaşları ile önemli ve karlı bir niş pazarı yönetmesine rağmen tasarımdan çok pazara yönelmiştir. Estetik olarak doğru bir tasarımın üretilmesinden çok geleneksel ve tutucu olan uluslararası pazar bilgilerinden yararlanılmıştır." (National Museums Scotland, nms.ac.uk, 2013d).

"1826 yılında iki Fransız kimyacı Jean Jacque Colin (1784-1865) ve Pierre Jean Robiquet (1780-1840), kök boyadaki alizarin ve purpurin boyarmaddelerini izole eden ilk kişiler olmuşlardır. Bulguları 1827 yılında Annales de Chimie XXXIV'de, Recherches sur la matière de la garance olarak yayınlanmıştır" (Winsor ve Newton 2003). Kök boyanın içinde yer alan boyarmadde "Alizarinin ismi ise Arapça al-Lizari sözcüğünden gelmektedir.” (Madder, 2013).

"1869 yılında alizarin ilk defa sentetik olarak üretilmiştir. Rekabetçi ve karlı olsa da; İskoç Türk Kırmızısı Sanayisi, Almanların geliştirdiği ucuz sentetik boya karşısında zor durumda kalmıştır. İşlerini korumak amacıyla Vale of Leven'daki İskoçya’nın önde gelen üç büyük üreticisi (William Stirling and Sons, John Orr Ewing and Co. and Archibald Orr Ewing and Co.) 1898 yılında United Turkey Red Company Ltd (UTR) adında birleşmişler ve 1961 yılına kadar üretim yapmışlardır." (National Museums Scotland, nms.ac.uk, 2013b). 
“1862 yılında Fransa'da 21000 hektar alanda kök boya üretimi yapılmaktadır. Alizarin gibi sentetik boyaların kullanımına en fazla direnç tarım sektöründen gelmiştir. Ancak sentetik alizarin ile boyama, doğal kök boya ile boyamaya göre üç kat daha ucuza yapılmıştır. Uygulamada kök boya ve muadilleri on dokuzuncu yüzyılın sonuna kadar piyasada birlikte yer almışlardır. Bu durum, kısmen alizarinin dayanıklılığının belirsiz olduğu düşünüldüğünden, kısmen de alizarinin pamuklu boyama için çıkmasına rağmen kök boyanın yün boyamacılıkta önemli olduğuna inanıldığından kaynaklanmıştır." (Travis, 1999: 285-312; Kirby vd., 2007: 69-95'den).

Hatta 1856 yılında ilk sentetik boyayı keşfeden William Henry Perkin, doğal boya bitkisinin yok olmaması için büyük bir alandaki kök boya (Rubai tinctorum L.) bitkisini bahçesinde senelerce korumuştur. ${ }^{5}$

"1868 de Alman kimyacılar C. Garbe ve C. Liebermann kök boyanın temel boyarmaddesi olan alizarinin formülünü bulmuştur. Büyük miktarlarda üretilmesi ile alizarin kısa sürede bütün dünyada önemli bir boyarmadde konumuna gelmiştir." (Karadağ, 2007: 75). Alizarinin sentetik olarak elde edilmesinin ardından pazar bitene kadar Fransa'da askeri üniformalar, Ingiltere'de ise tilki avcılarının giydiği geleneksel kırmızı ceketler kök boya ile boyanmıştır.

Günümüzde Türk Kırmızısı örneklerine ve onların tarihsel rollerine dikkat çekmek için Colouring the Nation adında bir proje uygulanmıştır. Bu proje, Edinburgh Üniversitesi, Scotland Ulusal Müzesi ve hükümet desteği ile gerçekleştirilmiştir. Proje kapsamında Turkey Red Collection adı altında 1830- 1940 yılları arasında üretilmiş desenlerden oluşan, kataloglar sergilemektedir. Bunlar, sektörün 1961'deki bitişinden sonra, Ulusal Müzeye devrettiği örnekleridir (National Museums Scotland, nms.ac.uk, 2013a, 2013c). Türk Kırmızısı tasarımları üreten firmalar, üretim süreçleri, siparişleri ve tasarımları hakkında tuttukları kayıtlarıyla tekstil tarihine büyük bir kaynak sağlamışlardır. The National Museums Scotland'da Türk Kırmızısı adı altnda yer alan koleksiyon, 200 kadar ciltli ciltsiz kaynak ile boyalı ve baskılı tekstillerden oluşan yaklaşık 40.000 parça içermektedir (feastbowl. wordpress, 2012).
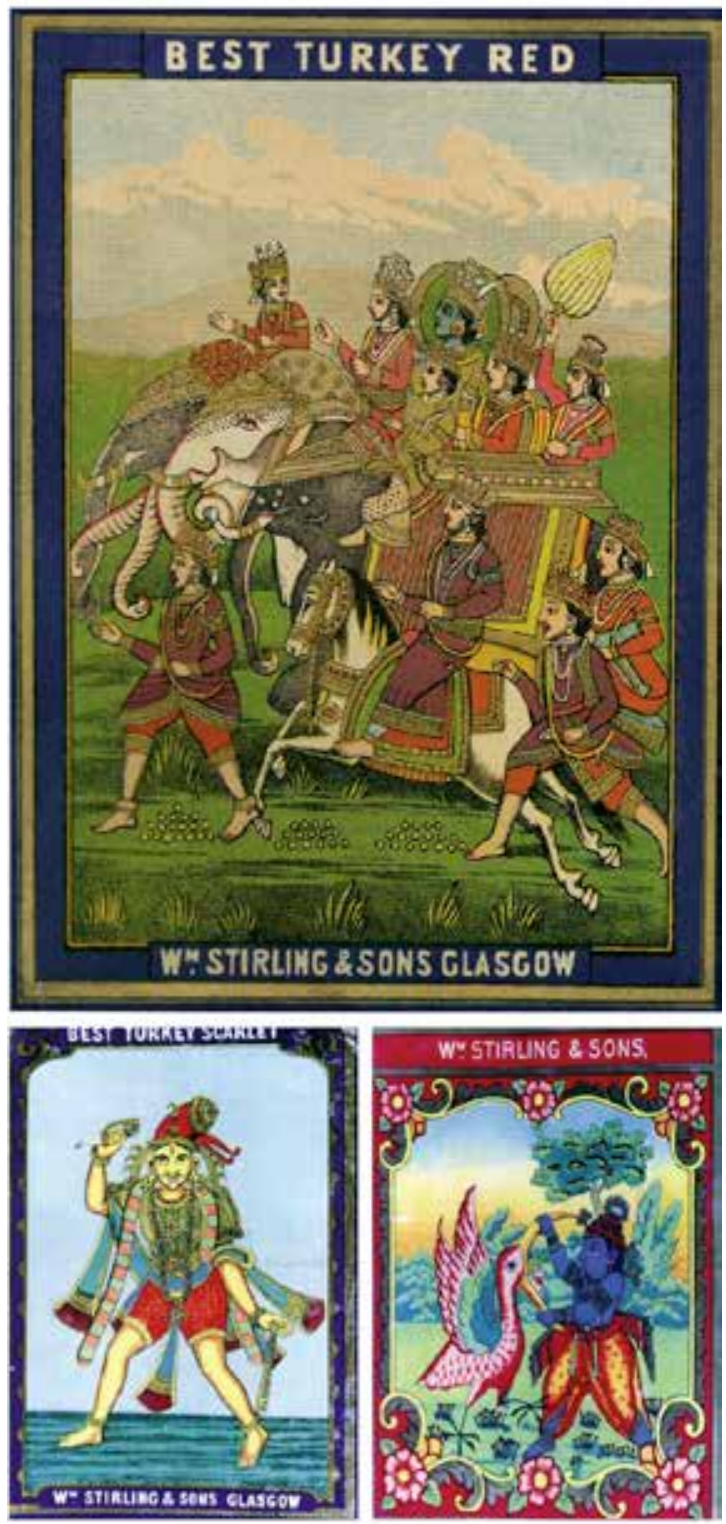

Resim 1. Türk Kırmızısı üreten firmaların kumaşlar için kullandığı etiket örnekleri.

Doğu'dan gelen deneyim Avrupalıların sistematik ve rekabetçi yapılarıyla birleşerek Türk Kırmızısı endüstrinin doğuşuna tanıklık etmiş ancak gelişmenin ve değişimin durdurulamaz yönü, elde edilen sonucun kalıcı olmasını engellemiştir. Türk Kırmızısı Endüstrisi, varlığını kökboya gibi bir doğal boyaya borçlu olduğundan, sentetik boyaların üretilmesiyle düşüşe geçmiş ve bitmiştir. Sektörün ardında bıraktığı örnekler ise Avrupa'nın endüstri tarihine ışık tutmakla kalmayıp, farklı coğrafyalarda üretilen değerlerin nasıl dünya kültür mirasına dönüştüğünü göstermektedir. 


\section{Sonuç}

Tekstil baskıcılığı, kumaş dokuma, baskıya hazır hale getirme ve boyama gibi karmaşık süreçlerin iyi bir şekilde bir arada olmasını gerektirmektedir. Bu zorunluluklarla birlikte belli bir desen talep edildiğinde, bilinmesi gereken teknik ve deneyimler katlanarak çoğalmaktadır. Kimyasal boyaların icadına kadar doğal boyarmaddelerle yapılan birçok işlem büyük ustalık ve nesillerden nesile aktarılan deneyimleri içermiştir. Önceleri krallar, asiller için üretilen renkli tekstiller, yeni ticaret yollarının açılması, teknoloji transferinin sağlanması, Rönesans düşüncesinin yayılması, küresel ticaretin gelişmesi vb. gibi etmenlerin sayesinde daha geniş kitlelere ulaşmaya başlamıştır. Özellikle pamuğun dünya ticaretinde önemli bir mal haline gelmesi, tekstil üretimini arttırmış, gözalıcı bir renk olan Türk Kırmızısı'nı aranan bir renk haline getirmiştir. Türk Kırmızısı denilince ise birçok alanda olduğu gibi Anadolu'nun jeopolitik ve kültürel konumu öne çıkmaktadır. Türk Kırmızısı'nı elde etmek için yapılan girişimler, Avrupa'da çeşitli boyahanelerin kurulmasını, tekstil boya ve baskıcılığının endüstriyel olarak kurulmasını ve kimya biliminin gelişimini sağlamışlardır.

\section{Notlar}

1 Bkz.: (Meller, Elffers, 1991: 88 178, 206).

2 Chafarcani: Beyaz çiçekli, kırmızı veya mor renkli baskılı kumaş (Riello, 2010).

32 Boucassin: Bogası, bohasi, Fransızca'da boucassin olarak bilinen ince pamuklu bir kumaş türü (İnalcık, 2008: 112).

4 Bkz: (Persoz,1846: 173).

5 Bkz.: (İşmal, 2011: 23).

\section{Kaynakça}

Aikin, J. (1795). A Description of The Country from Thirty to Forty Miles Round Manchester, London: David \& Charles Publishers.

Abdel-Kareem, Omar (2012). "History of Dyes Used in Different Historical Periods of Egypt", Research Journal of Textile and Apparel (16/4): 79-92.

Brunello, Franco (1973). The Art of Dyeing in The History of Mankind, ed. Neri Pozza, translation: Bernard Hickey, Vicenza: Officine Grafiche STA.

Chapman S. et Chassagne, S. (1981). European Textile Printers in the Eighteenth Century, A Study of Peel and Oberkampf, London: Heinemann.
Delamare, François ve Guineau, Bernard (2007). Renkler ve Malzemeleri, çev: Orçun Türkay, İstanbul: YKM Yayınları.

Driessen, L. A. (1944). "Calico Printing and The Cotton Industry in Holland", Ciba Review (48): 1749.

Floud, Peter C. (1960). "The Origins of English Calico Printing”, Journal of the Society of Dyers and Colourists (86): 275-81.

Fukasawa, Katsumi (1987). Toilerie et Commerce du Levant: d'Alep a' Marseille, Paris: Presses du CNRS.

Galan , A. Nieto (2001). "Colouring Textiles - A History of Natural Dyestuffs in Industrial Europe", Boston Studies in the Philosophy of Science, Boston: Springer, 217.

Goffer, Z. (1980). Archaeological Chemistry, A Source Book on the Applications of Chemistry to Archaeology, New York: John Wiley \& Sons.

İnalcık, Halil (2008). Türkiye Tekstil Tarihi, İstanbul: İş Bankası Yayınları.

İşmal, Ş. Özlenen Erdem (2011). "Boyarmadde Endüstrisinin Öncüsü: Bir Bilim Adamı ve Entelektüel olarak Sir William Henry Perkin", Yedi, Sanat ve Tasarım Dergisi (6): 23-30.

Karadağ, Recep (2007). Doğal Boyamacılık, Ankara: T.C. Kültür ve Turizm Bakanlığı Yayınları.

Karadağ Recep ve Dölen, Emre (2007). "Re-Examınation of Turkey Red, Annali di Chimica", Società Chimica Italiana (97): 583589.

Kirby, Jo. (1987). "The Preparation of Early Lake Pigments: A Survey", Dyes on Historical and Archaeological Textiles (6): 12-18.

Koren, Z.C. (1993). The Colors and Dyes on Ancient Textiles in Israel, Colors from Nature: Natural Colors in Ancient Times, ed. Sorek, C. and Ayalon, E., Tel Aviv, Israel: Eretz-Israel Museum.

Masson, P. (1896). Histoire du Commerce Français dans le Levant au XVII ${ }^{\mathrm{e}}$ Siècle, Paris.

Meller, Susan ve Elffers, Joost (1991). Textile Designs, New York: Harry N. Abrams,

Inc.Musson, A. E. ve Robinson, Eric (1969). Chemical Developments in Dyeing, in

Science and Technology in the Industrial Revolution, London: University of Manchester.

Pérez, Liliane Hilaire (2000). L'Invention Téchnique au Siècle des Lumières, Paris: Albin Michel.

Pérez, Liliane Hilaire (2002). "Cultures Techniques et Pratiques de l'Échange", Entre Lyon et le Levant: Inventions et Réseaux au XVIII ${ }^{e}$ Siècle, Revue d'Histoire Moderne et Contemporaine, (49): 1-105. 
Pérez, Liliane Hilaire and Verna, Catherine (2006). "Dissemination of Technical Knowledge in The Middle Ages and The Early Modern Era New Approaches and Methodological Issues", Technology and Culture, (47): 539-565.

Persoz, J. (1846). Traité Théorique et Pratique de L'Impression des Tissus, ed.Victor Masson, Paris: Victor Masson.

Riello, Giorgio (2010). "Asian Knowledge and The development of Calico Printing in Europe in The Seventeenth and Eighteenth Centuries", Journal of Global History (5): 1-28.

Raveux, Olivier (2004). "Espaces et Technologies dans la France Méridionale d'Ancien Régime: l'Example de l'Indiennage Marseillais (1648-1793)", Annales du Midi (116): 70-155.

Raveux, Olivier (2008). "Du Commerce a`la Production: l'Indiennage Européen et l'Acquisition des Téchniques Asiatiques au XVIle Siècle", Féerie Indienne: des Rivages de I'Inde au Royaume de France, Mulhouse: Musée de l'Impression sur Étoffes.

Robinson, Stuart (1969). A History of Printed Textiles, London: Studio Vista.

Schwartz, P. R. (1956). "French Documents on Indian Cotton Painting 1: The Beaulieu ms, c. 1734", Journal of Indian Textile History (2): $5-23$

Souza, George Bryan (2004). "Dyeing Red: S.E. Asian Sappanwood in the Seventeenth and Eighteenth centuries", Oriente (8): 40-58.

Travis, Anthony S. (1999). Heinrich Caro, Chemist and Calico Printer, and the Changeover from Natural to Artificial Dyes, Natural Dyestuffs and Industrial Culture in Europe.

Turnbull, Geoffrey (1947). A History of The Calico Printing Industry of Great Britain, Altrincham, Ches.: John Sherratt and Son

Wadsworth, A. P. and Mann, Julia de Lacy (1932). The Cotton Trade and Industrial Lancashire, 1600-1780, Manchester: Manchester University Press.

Yılmazçelik, İbrahim (1985). XIX. Yüzyılın Illk Yarısında Diyarbakır (1790-1840), Ankara.

\section{Internet Kaynakları}

(Colorantshistory, 2013) Howcraft, Deborah, Paterson, Carole and Travis, Anthony S. Turkey Red Dyeing in Blackley, A Chapter in the History of Dyeing", excerpt from Pro Memoria-Turkey Red Dyeing and Blackley, Wilfred Herbert Cliffe, http://www.colorantshistory.org/ TurkeyRed.html, (10.09.2013)

(Colouringthenation, 2013) "Colouring the Nation,Turkey Red' and Other Decorative Textiles in Scotland's Culture and Global Impact, 1800 to Present, Turkey Red and the Vale of Leven" http://colouringthenation.wordpress.com/turkey-red-inscotland/ (21.10.2013)

Druding, Susan C. (2012). Dye History from 2600 BC to the 20th Century.http://www.straw.com/sig/dyehist.html (03.02.2013)

Eddy, Celia (2012). "The History of Turkey Red" http://bqsg. quiltersguild.org.uk/blog/the-history-of-turkey-red 28.10.2013

Faroqhi, Suraiya (2005). "Ludwig Maximilians University Ottoman Cotton Textiles, 1500 to 1800", GEHN Conference University of Padua http://www.lse.ac.uk/ economicHistory/Research/GEHN/GEHNPDF/ PaduaFaroqhiPaper.pdf, 17-19 (06.09.2013)

(Feastbowl.wordpress) Turkey Red: A Study in Scarlet http://feastbowl.wordpress.com/category/projects/ turkey-red/ (22.10.2013)

Kirby, Jo ve Whit, Raymond (1996). The Identification of Red Lake Pigment Dyestuffs and a Discussion of their Use, London: National Gallery Technical Bulletin (17): 56-80 http://www. nationalgallery.org.uk/upload/pdf/kirby_white1996.pdf (01.09.2013)

Kirby, Jo, Spring, Marika, Higgitt, Catherine (2007). "The Technology Eighteenth- and Nineteenth Century-Red Lake Pigment", National Galery Tecnical Bulletin (28): 69-95. http://www. nationalgallery.org.uk/upload/pdf/kirby_spring_ higgitt2007.pdf (19.09.2013)

Lowengard, Sarah ( 2006). The Creation of Color in 18th-Century Europe, Industry and Ideas Turkey Red, New York: Columbia University Press and Gutenberg-e. http://www. gutenberg-e.org/lowengard/C_Chap36.html, (12.09.2013)

(Madder, 2013) Madder, http://webpages.charter.net/siospins/ pubs/Madder.pdf (06.09.2013)

(National Museums Scotland, nms.ac.uk, 2013a) National Museums Scotland, About Colouring the Nation, http://www.nms. ac.uk/turkey_red/colouring_the_nation/about_ colouring_the_nation.aspx (17.10.2013)

(National Museums Scotland, nms.ac.uk, 2013b) National Museum of Scotland, Printed cottons in Scotland, http://www.nms. ac.uk/turkey_red/colouring_the_nation/research/ turkey_red_in_scotland/printed_cottons_in_scotland. aspx (06.09.2013)

(National Museums Scotland, nms.ac.uk, 2013c) National Museums Scotland, The Turkey red process, http://www.nms.ac.uk/ turkey_red/colouring_the_nation/research/dyeing_and_ printing_techniques/the_turkey_red_process.aspx (22.10.2013) 
(National Museums Scotland, nms.ac.uk, 2013d) National Museum of Scotland, Styles and patterns, http://www.nms.ac.uk/ turkey_red/colouring_the_nation/research/styles_and_ patterns.aspx, (06.09.2013)

Prance, Ghillean and Nesbitt, Mark (2005). The Cultural History of Plants, New York: Routledge. http://permaculteur. free.fr/ecoanarchisme/Cultural\%20History\%20 of\%20 Plants\%200415927463red.pdf p.305-306 (12.05.2013)

Raveux, Olivier (2008). "À la Façon du Levant et de Perse: Marseille et la Naissance de l'Indiennage Européen (1648-1689)", Rives Nord-Méditerranéennes http://rives.revues. org/1303 p. $37-51$ (7.09.2013)

Sardar, Marika (2012). "Indian Textiles: Trade and Production" http:// www.metmuseum.org/toah/hd/intx/hd_intx.htm .04.01.2014)

Shwartz, P. R. (1969). "Printing on Cotton at Ahmedabad, India in 1678", Translation: Margaret Hall, Ahmedabad: Calico Museum of Textiles, India, Museum Monograph No.1. http:// www.cs.arizona.edu/patterns/weaving/monographs/ spr_prnt.pdf (20.11.2013)

(Silk-Road)http://www.silk-road.com/artl/marcopolo.shtml 04.01.2014

Travis, Anthony S. (1994). Madder Red-A Revolutionary Colour Chemistry \& Industry, (3) 28. http:// www.colorantshistory.org/MadderRed.html (15.09.2013) (Westdunbarton) The River Leven Heritage Trail, http://www.westdunbarton.gov.uk/media/2619077/river-leven.pdf, (20.1.2013)

Winsor and Newton (2003). "The History and Production of Rose Madder and Alizarin Pigments" http://www.winsornewton. com/resource-centre/product-articles/rose-madderandalizarin (06.09.2013)

\section{Görsel Kaynak}

Resim 1. Türk Kırmızısı üreten firmaların kumaşlar için kullandığı etiket örnekleri.(http://www.west-dunbarton.gov.uk/ media/2619077/river-leven.pdf, (20.1.2013) 